\title{
PENDIDIKAN KESEHATAN DENGAN MEDIA BOOKLET ANTI ISPA (BOOKIS) TERHADAP PERILAKU PENCEGAHAN ISPA PADA IBU BALITA
}

\author{
Ni Putu Diah Ameliya Putri ${ }^{1}$, I Ketut Gama ${ }^{2}$, \\ ${ }^{1,2}$ Jurusan Keperawatan, Poltekkes Kemenkes Denpasar \\ Denpasar, Bali, Indonesia \\ e-mail:Putriamelya90@gmail.com¹,gama_bali@yahoo.co.id ${ }^{2}$
}

\begin{abstract}
Upper Respiratory TractInfections (URTI) is an acute infection involving the organ of the upper respiratory tract and the bottom of which can cause a range of illnesses from mild infection to weight and turn off. The purpose of this research was to determine the effect of health education with anti-URTI Booklet media on URTI prevention behavior in mothers of children under five years old. This research was conducted in April-May 2019. This type of research is a quasy experiment with a pre-test and post-test design. This research used 61 people as a sample with used the total sampling technique. The results of this study indicate that from 61 respondents before given treatment had good behavioral categories as much as $57.4 \%$ and after being treated $96.7 \%$ had good value categories. Hypothesis testing using the Wilcoxon test results in a $p$ valueof 0,000 ( $p$ value $<0.05$ ) which means that there is an effect of health education with the Anti-URTI Booklet media on URTI prevention behavior in mothers of children under five years old. Based on the results of the study it is suggested that it can improve efforts to prevent URTI in infants using the Anti-URTI Booklet (BOOKIS).
\end{abstract}

Keywords: health education; media Booklet; preventive behavior

ABSTRAK.Infeksi Saluran Pernapasan Akut (ISPA) adalah infeksi akut yang melibatkan organ saluran pernapasan bagian atas dan bagian bawah yang dapat menyebabkan berbagai macam penyakit dari infeksi ringan sampai berat dan mematikan. Tahun 20a16 didapatkan sebanyak 5,6 juta anak dibawah lima tahun mengalami. Tujuan penelitian ini adalah untuk mengetahui pengaruh pendidikan kesehatan dengan media BookletAnti ISPA (BOOKIS) terhadap perilaku pencegahan ISPA pada ibu balita. Penelitian ini dilakukan pada bulan April-Mei 2019. Jenis Penelitian ini adalah quasyexperiment dengan rancangan pretest dan posttestdesign. Jumlah sampel 61 orang menggunakan teknik total sampling. Hasil penelitian ini menunjukkan bahwa dari 61 responden sebelum diberikan perlakuan memiliki kategori perilaku baik sebanyak 57,4\% dan setelah diberi perlakuan 96,7 \% memiliki kategori nilai baik. Uji hipotesis menggunakan uji Wilcoxondidapatkan hasil $\mathrm{p}$ valuesebesar 0,000 ( $\mathrm{p}$ value $<0,05$ ) yang berarti ada pengaruh pendidikan kesehatan dengan media Booklet Anti ISPA terhadap perilaku pencegahan ISPA pada ibu balita. Berdasarkan hasil penelitian disarankan agar dapat meningkatkan upaya pencegahan ISPA pada balita dengan menggunakan media Booklet Anti ISPA (BOOKIS).

Kata kunci: pendidikan kesehatan; media Booklet;perilaku pencegahan 


\section{PENDAHULUAN}

Infeksi Saluran Pernapasan Akut (ISPA) adalah infeksi akut yang melibatkan organ saluran pernapasan bagian atas dan bagian bawah yang dapat menyebabkan berbagai macam penyakit dari infeksi ringan sampai berat. Penyakit ini dapat menyerang saluran pernapasan mulai dari hidung sampai alveoli termasuk andeksanya seperti sinus, rongga telinga, pleura. ISPA termasuk Air Bone Disease yang penularan penyakitnya melalui udara (1)(2). Tahun 2016 sebanyak 5,6 juta anak dibawah lima tahun mengalami kematian dan 16\% diakibatkan oleh pneumonia yang merupakan salah satu manifestasi dari ISPA(3). Insidensi ISPA di Bali menunjukkan angka yang berfluktuasi setiap tahunnya, tahun 2018 prevalensi ISPA sebesar $49,36 \%$ (4). Kabupaten Gianyar merupakan kabupaten dengan prevalensi kasus ISPA tertinggi di Provinsi Bali sebesar 28,8\%. Angka kejadian ISPA di Kabupaten Gianyar tahun 2017 dengan jumlah 22.274 kasus dan tahun 2018 ISPA menempati peringkat pertama dari 10 besar penyakit pada pasien di UPT Kesmas Kabupaten Gianyar sejumlah 23.979 kasus (5).

Prevalensi kasus ISPA tertinggi terdapat di wilayah kerja UPT Kesmas Sukawati II, dimana ditemukan sebanyak 2.043 kasus dan sebanyak 94 balita mengalami pneumonia (5). Desa Singapadu Tengah tahun 2018 dengan prevalensi ISPA tertinggi. ditemukan di Banjar Negari Desa Singapadu Tengah dengan jumlah kasus sebesar 143 kasus dan 4 balita dengan pneumonia pada tahun 2018 (6).
ISPA pada balita jika tidak ditangani dengan baik dapat menyebabkan komplikasi yang serius. Pemberian pendidikan kesehatan tentang ISPA merupakan usaha atau kegiatan untuk membantu individu, kelompok atau masyarakat terutama ibu untuk meningkatkan kemampuan mereka dalam pencegahan dan penanganan ISPA sehingga kualitas kesehatan tercapai secara optimal. Pendidikan kesehatan merupakan gambaran penting dan bagian dari peran perawat yang profesional dalam upaya preventif dengan promosi kesehatan dan pencegahan penyakit (7). Pemberian pendidikan kesehatan dapat menggunakan media pendidikan kesehatan (8).

Media yang dapat digunakan dalam pemberian pendidikan kesehatan adalah Booklet. Bookletberfungsi untuk meneruskan pesan yang diterima kepada orang lain, karena bahasa pendidikan dapat disampaikan lebih mudah (9). Penelitian yang dilakukan oleh (10) mengenai penyuluhan dengan media bookletterhadap praktik ibu dalam memberikan pengetahuan personal hygiene saat menstruasi pada anak dengan kebutuhan khusus didapatkan hasil dengan $\mathrm{P}$ Value $0,000(\mathrm{p}<0,05)$. Hal tersebut membuktikan bahwa penyuluhan dengan media booklet memiliki pengaruh yang signifikan dalam meningkatkan praktik ibu dalam memberikan personal hygiene saat menstruasi pada anak dengan kebutuhan khusus.

Penggunaan media diharapkan mampu memberikan pengaruh terhadap pengetahuan, sikap dan tindakan ibu dalam melakukan pencegahan ISPA pada balita. Oleh karena itu penelitian 
ini bertujuan untuk meneliti pengaruh pendidikan kesehatan dengan media BookletAnti ISPA (BOOKIS) terhadap perilaku pencegahan ISPA pada ibu balita.

\section{METODE}

Penelitian ini merupakan penelitian kuantitatif pre-eksperimental designs. Rancangan penelitian yang diganakan adalah Onegrouppretestposttest. Populasi dalam penelitian ini adalah semua ibu balita di Banjar Negari, berjumlah 61 orang dengan menggunakan teknik totalsampling. Data yang dikumpulkan adalah data primer yaitu identitas responden, perilaku pencegahan dengan metode kuisioner. Data sekunder yang dikumpulkan adalah data jumlah ibu balita dan pendidikan kesehatan mengenai penyakit menular apa saja yang sudah pernah diberikan yang didapat dari dokumen posyandu Banjar Negari. Teknik analisa data yang digunakan yaitu analisis univariatdananalisisbivariat. Data yang dianalisis univariat meliputi usia, pendidikan, pekerjaan, pengetahuan, sikap, tindakan dan perilaku. Data pendidikan, pekerjaan, pengetahuan, sikap, tindakan, perilaku termasuk data kategorik, sehingga dianalisis dengan statistik deskriptif, yaitu menggunakan distribusi frekuensi dan dijabarkan persentase dari masing-masing variabel. Untuk data usia, termasuk data numerik. Semua data disajikan dalam bentuk tabel. Untuk analisis bivariat, menggunakan uji Wilcoxonkarena termasuk data kategorik.

\section{HASIL DAN PEMBAHASAN}

Besar sampel yang telah diperoleh yaitu sebanyak 61 orang responden dari jumlah populasi target sebanyak 61 orang. Karakteristik responden yang diteliti dapat diuraikan berdasarkan usia dan jenis kelamin yang dijabarkan dalam bentuk tabel, tabel 1 distribusi karakteristik responden berdasarkan usia dimana sebagian besar responden berusia 20-26, karakteristik responden berdasarkan pekerjaan sebagian besar responden dalam penelitian ini bekerja sebagai wiraswasta,dan distribusi responden berdasarkan pendidikan sebagian besar responden berpendidikanterahir SMA/SMK.

Tabel 1

Distribusi Frekuensi Karakteristik Responden Berdasarkan Usia

\begin{tabular}{cccc}
\hline No & $\begin{array}{c}\text { Usia } \\
\text { (tahun) }\end{array}$ & (n) & $(\boldsymbol{\%})$ \\
\hline 1 & $20-26$ & 33 & 54,1 \\
2 & $27-33$ & 25 & 41,0 \\
3 & $34-40$ & 3 & 4,9 \\
\hline & Jumlah & 61 & 100 \\
\hline
\end{tabular}

karakteristik responden berdasarkan usia dimana sebagian besar responden $54,1 \%$ berusia $20-26$ tahun.

Tabel 2

Distribusi Frekuensi Karakteristik Responden Berdasarkan Pendidikan

\begin{tabular}{|c|c|c|c|}
\hline No & Pendidikan & $(\mathbf{n})$ & $(\boldsymbol{\%})$ \\
\hline 1 & SD & 2 & 3,3 \\
\hline 2 & SMP & 13 & 13 \\
\hline 3 & SMA/SMK & 34 & 55,7 \\
\hline 4 & $\begin{array}{c}\text { Perguruan } \\
\text { Tinggi }\end{array}$ & 12 & 19,7 \\
\hline & Jumlah & 61 & 100 \\
\hline
\end{tabular}

Tabel 2 distribusi karakteristik responden berdasarkan tingkat 
Ni Putu Diah Ameliya PutridanI Ketut Gama. Desember 2020. 13 (2). 87-96

pendidikan, sebagian besar responden $55,7 \%$ berpendidikan terakhir SMA/SMK.

Tabel 3

Distribusi Frekuensi Karakteristik Responden Berdasarkan Pekerjaan

\begin{tabular}{|c|c|c|c|}
\hline No & Pekerjaan & $(\mathbf{n})$ & $(\boldsymbol{\%})$ \\
\hline 1 & Buruh & 6 & 9.8 \\
\hline 2 & Petani & 6 & 9.8 \\
\hline 3 & PNS & 9 & 14.8 \\
\hline 4 & Swasta & 14 & 23.0 \\
\hline 5 & $\begin{array}{c}\text { Tidak } \\
\text { bekerja }\end{array}$ & 10 & 16.4 \\
\hline 6 & Wiraswasta & 16 & 26.2 \\
\hline & Jumlah & 61 & 100 \\
\hline
\end{tabular}

Tabel 3 menunjukkan bahwa sebagian besar yaitu $26,2 \%$ responden bekerja sebagai wiraswasta.

Tabel 4

Distribusi Frekuensi Pengetahuan tentang Pencegahan ISPA Sebelum dan Setelah Diberikan Pendidikan Kesehatan dengan Media BookletAnti ISPA (BOOKIS)

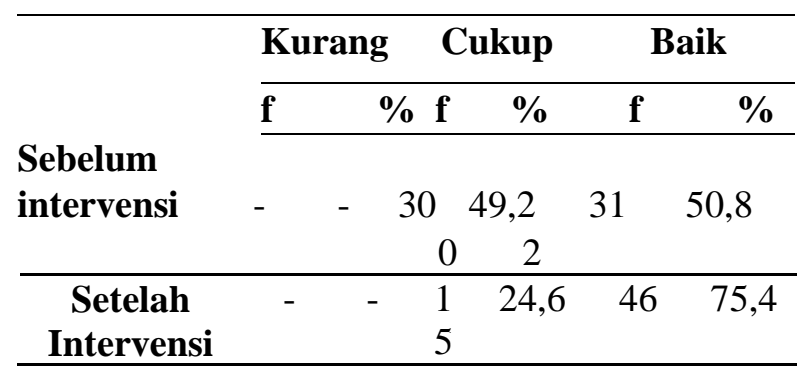

Tabel 4 menunjukkan bahwa sebelum diberikan pendidikan kesehtan dengan media Booklet 30 orang (49,2\%) responden memiliki pengetahuan cukup dan sebanyak 31 orang $(50,8 \%)$ memiliki pengetahuan baik tentang pencegahan ISPA. Hasil tersebut menunjukkan sebagian besar ibu balita belum memahami tentang faktorfaktor yang mempengaruhi dan meningkatkan risiko terjadinya ISPA pada balita. Menurut (1) faktor-faktor yang mempengaruhi tingkat pengetahuan seseorang adalah pendidikan, informasi, pekerjaan, lingkungan, sosial budaya dan ekonomi, pengalaman dan usia. Sedangkan setelah diberikan pendidikan kesehatan dengan media Booklet Anti ISPA (BOOKIS) dari 61 orang responden sebanyak 15 resonden (24,6\%) memiliki pengetahuan cukup dan sebanyak 46 responden $(75,4 \%)$ pengetahuannya baik tentang pencegahan ISPA. Hal ini dipengaruhi oleh adanya pendidikan kesehatan dengan media Booklet yang membuat responden memiliki pengetahuan tentang penyakit ISPA, kemudian adanya informasi yang disampaikan pada saat pendidikan kesehatan yang dapat meningkatkan kesadaran responden untuk menjaga kesehatan khususnya dalam pencegahan ISPA pada balita. Pendidikan kesehatan dengan media Booklet mampu meningkatkan pengetahuan responden yang sebelumnya cukup meningkat menjadi baik sebanyak 16 responden setelah diberikan pendidikan keehatan dengan media Booklet.

Hasil ini sejalan dengan penelitian yang dilakukan oleh (11) tentang pengaruh pendidikan dengan media leafletterhadap pengetahuan ibu tentang penatalaksanaan ISPA di Posyandu Bambu Kuning Jambi menunjukan bahwa ada pengaruh yang signifikan pada pendidikan kesehatan terhadap pengetahuan ibu tentang penatalaksanaan ISPA di Posyandu Bambu Kuning Jambi.

Tabel 5

Distribusi Frekuensi Sikap terhadap Pencegahan ISPA Sebelum dan Setelah Diberikan Pendidikan Kesehatan 
Ni Putu Diah Ameliya PutridanI Ketut Gama. Desember 2020. 13 (2). 87-96

dengan Media BookletAnti ISPA (BOOKIS)

\begin{tabular}{|c|c|c|c|c|c|}
\hline \multirow{3}{*}{$\begin{array}{l}\text { Sebelum } \\
\text { Intervensi }\end{array}$} & Kurang & \multicolumn{2}{|c|}{ Cukup } & \multicolumn{2}{|c|}{ Baik } \\
\hline & f & $\%$ f & $\%$ & f & $\%$ \\
\hline & - & 16 & 26,2 & 45 & 73,8 \\
\hline $\begin{array}{c}\text { Setelah } \\
\text { Intervensi }\end{array}$ & - & 1 & 1,6 & 60 & 98,4 \\
\hline
\end{tabular}

Tabel 5 sebelum diberikan

pendidikan kesehatan dengan media Booklet Anti ISPA (BOOKIS) sebanyak 16 responden ( $26,2 \%$ ) memiliki sikap cukup dan sebagian besar yaitu 45 responden $(73,8 \%)$ sikapnya baik terhadap pencegahan ISPA. Hasil tersebut menunjukkan bahwa beberapa responden belum memiliki sikap yang baik dalam pencegahan ISPA. Menurut Azwar (2013) faktor-faktor yang mempengaruhi sikap seseorang adalah pengalaman pribadi, pengaruh orang lain yang dianggap penting, media massa, kebudayaan, lembaga pendidikan dan lembaga agama, dan faktor emosional. Setelah diberikan pendidikan kesehatan dengan media Booklet Anti ISPA (BOOKIS) sebagian besar yaitu 60 orang $(98,4 \%)$ memiliki sikap baik terhadap pencegahan ISPA. Hal ini dipengaruhi oleh adanya pendidikan kesehatan dengan media Booklet yang dapat memberikan penanaman konsep moral dan ajaran tentang pentingnya pendidikan kesehatan ISPA selain itu dalam pemberian pendidikan kesehatan dengan media Booklet didukung dengan ilustrasi yang mengandaikan keluarga responden atau responden terkena dampak dari penyakit ISPA yang berat. Ilustrasi ini dibuat untuk meninggalkan kesan yang kuat dan mampu merubah sikap responden tentang pentingnya pencegahan penyakit ISPA. Hasil penelitian ini sejalan dengan penelitian (12) tentang pengaruh pendidikan kesehatan ISPA terhadap sikap ibu dalam pencegahan ISPA pada balita di Desa Pengalihan Enok menunjukkan hasil bahwa nilai signifikansi $\mathrm{P}$ value $0,0002<$ 0,05 hal tersebut menunjukkan bahwa ada pengaruh pendidikan kesehatan ISPA terhadap sikap ibu dalam pencegahan ISPA pada balita.

Tabel 6

Distribusi Frekuensi Tindakan dalam Pencegahan ISPA Sebelum dan Setelah Diberikan Pendidikan Kesehatan dengan MediaBooklet Anti ISPA (BOOKIS)

\begin{tabular}{|c|c|c|c|c|c|}
\hline \multirow{3}{*}{$\begin{array}{l}\text { Sebelum } \\
\text { Intervensi }\end{array}$} & Kurang & \multicolumn{2}{|c|}{ Cukup } & \multicolumn{2}{|c|}{ Baik } \\
\hline & f & $\% \mathbf{f}$ & $\%$ & f & $\%$ \\
\hline & - & -28 & 45,9 & 33 & 54,2 \\
\hline $\begin{array}{c}\text { Setelah } \\
\text { Intervensi }\end{array}$ & - & 24 & 39,3 & 37 & 60,7 \\
\hline
\end{tabular}

Tabel 6 menunjukkan bahwa tindakan sebelum diberikan pendidikan kesehatan dengan media Booklet Anti ISPA (BOOKIS) sebanyak 28 orang $(45,9 \%)$ responden memiliki tindakan cukup dan sebanyak 33 responden $(54,2 \%)$ tindakannya baik dalam pencegahan ISPA, hal tersebut menjukkan bahwa ada beberapa responden yang belum memiliki tindakan yang baik dalam pencegahan ISPA. Untuk terwujudnya suatu tindakan maka diperlukan faktor pendukung atau suatu kondisi yang memungkinkan, seperti fasilitas dan faktor dukungan (10)

Setelah diberikan pendidikan kesehatan dengan media Booklet Anti ISPA (BOOKIS) sebanyak 37 orang $(60,7 \%)$ tindakannya baik dalam pencegahan ISPA. Menurut (13) praktik (practice) atau tindakan adalah melaksanakan atau mempraktikkan apa yang diketahui dan disikapi oleh seseorang. Persepsi seseorang akan timbul 
melalui proses mengenal atau memilih berbagai objek sehubungan dengan tindakan yang akan diambil. Pengetahuan adalah dasar untuk melakukan suatu tindakan sesuai dengan pengetahuannya Hasil ini sejalan dengan penelitian yang dilakukan oleh (11) tentang pengaruh pendidikan dengan media leaflet terhadap pengetahuan ibu tentang penatalaksanaan ISPA di Posyandu Bambu Kuning Jambi menunjukan bahwa ada pengaruh yang signifikan pada pendidikan kesehatan terhadap pengetahuan ibu tentang penatalaksanaan ISPA di Posyandu

Bambu Kuning Jambi

Tabel 7

Distribusi Frekuensi Perilaku Pencegahan ISPA Sebelum dan Setelah Diberikan Pendidikan Kesehatan dengan Media Booklet Anti ISPA (BOOKIS)

\begin{tabular}{|c|c|c|c|c|c|c|}
\hline \multirow{2}{*}{$\begin{array}{l}\text { Sebelum } \\
\text { Intervensi }\end{array}$} & \multicolumn{2}{|c|}{$\begin{array}{c}\text { Kuran } \\
\text { g }\end{array}$} & \multicolumn{2}{|c|}{ Cukup } & \multicolumn{2}{|c|}{ Baik } \\
\hline & f & & $6 \mathrm{f}$ & $\%$ & $\mathbf{f}$ & $\%$ \\
\hline & - & & -26 & 42,6 & 35 & 57,4 \\
\hline Setelah & - & - & & & 59 & 96,7 \\
\hline Intervensi & & & 2 & 3,3 & & \\
\hline
\end{tabular}

Tabel 7 menunjukkan bahwa sebelum diberikan pendidikan kesehatan dengan media Booklet Anti ISPA (BOOKIS) terdapat 26 responden $(57,4 \%)$ perilakunya cukup, dan 35 reponden $(57,4 \%)$ memiliki perilaku baik. Hal tersebut menunjukkan bahwa beberapa responden belum memiliki perilaku yang baik dalam pencegahan ISPA. Kondisi tersebut menjadikan pentingnya pendidikan kesehatan dengan media Booklet Anti ISPA (BOOKIS) terhadap perilaku pencegahan ISPA. Pendidikan kesehatan bertujuan agar seseorang mampu mempelajari apa yang dapat dilakukan sendiri dan bagaimana caranya meminta pertolongan pada sarana pelayanan kesehatan formal (12).

Perilaku pencegahan ISPA dipengaruhi oleh beberapa faktor yaitu faktor internal dan eksternal. Faktor internal yang mempengaruhi perilaku pencegahan ISPA yaitu tingkat kecerdasan, tingkat emosional dan jenis kelamin sedangkan faktor eksternalnya yaitu lingkungan, sosial budaya, politik, ekonomi, agama dan pendidikan. Selain faktor-faktor tersebut, terdapat faktorfaktor lain yang mempengaruhi perilaku pencegahan ISPA yaitu faktor predisposisi, faktor pendukung, dan faktor pendorong. Faktor predisposisi yaitu faktor yang mempengaruhi perilaku seperti pengetahuan, sikap, kepercayaan, dll. Faktor pendukung seperti tersedianya sarana dan prasrana. Faktor pendorong seperti sikap dan perilaku petugas kesehatan(13). Perilaku pencegahan ISPA salah satunya dipengaruhi oleh pengetahuan, dimana pengetahuan merupakan apa yang diketahui oleh seseorang tentang sesuatu yang terjadi setelah melakukan pengindraan terhadap suatu obyek, dengan tahu dapat membentuk perilaku seseorang yang mencakup kemampuan kognitif, afektif, dan psikomotor (13).

Sedangkan setelah diberikan pendidikan kesehatan dengan media Booklet Anti ISPA (BOOKIS) dari 61 orang responden sebanyak 2 resonden $(3,3 \%)$ memiliki pengetahuan cukup dan sebanyak 59 responden $(96,7 \%)$ perilakunya baik tentang pencegahan ISPA. Hal ini dipengaruhi oleh adanya pendidikan kesehatan dengan media . 
Booklet yang membuat responden memiliki perilaku pencegahan yang baik tentang penyakit ISPA. Wawasan dan pemikiran yang luas di bidang kesehatan akan mempengaruhi perilaku individu dalam menyikapi suatu penyakit, sehingga jika sudah mengetahui sesuatu hal tentang bidang kesehatan nantinya akan mampu mengaplikasikannya ke dalam kehidupan nyata seperti mampu memanfaatkan fasilitas pelayanan kesehatan maupun mencegah terjadinya penyakit ISPA seperti, memberikan ASI ekslusif, imunisasi, menjaga kesehatan gizi agar tetap baik, menjaga kebersihan lingkungan. Hasil penelitian ini sejalan dengan penelitian (9) tentang pengaruh pendidikan kesehatan ISPA terhadap sikap ibu dalam pencegahan ISPA pada balita di Desa Pengalihan Enok menunjukkan hasil bahwa nilai signifikansi $\mathrm{P}$ value $0,002<$ 0,05 hal tersebut menunjukkan bahwa ada pengaruh pendidikan kesehatan ISPA terhadap sikap ibu dalam pencegahan ISPA pada balita.

Tabel 8

Analisis Bivariat Pengaruh Pemberian Pendidikan Kesehatan dengan Media Booklet Anti ISPA (BOOKIS) terhadap Perilaku Pencegahan ISPA

Perilaku Setelah

\begin{tabular}{lllll} 
& & & & Juml \\
\cline { 2 - 3 } Perilaku & Kurang & Cukup & Baik & ah \\
Sebelum & & & & \\
\cline { 2 - 3 } & & &
\end{tabular}

\begin{tabular}{|c|c|c|c|c|}
\hline Jumlah & 2 & 3,3 & $\begin{array}{cc}59 & 96, \\
& 7 \\
\end{array}$ & $\begin{array}{l}6 \\
1 \\
\end{array}$ \\
\hline & & & $\begin{array}{c}10 \\
0\end{array}$ & \\
\hline
\end{tabular}

Berdasarkan interpretasi tabel 8 diatas, didapatkan bahwa perilaku ibu balita yang cukup dalam pencegahan ISPA sebelum diberikan pendidikan kesehatandengan media Booklet Anti ISPA (BOOKIS) sebagian besar menjadi perilaku yang baik dalam pencegahan ISPA setelah diberikan pendidikan kesehatan dengan media Booklet Anti ISPA (BOOKIS) dengan persentase $39,3 \%$, perilaku ibu balita yang baik dalam pencegahan ISPA sebelum diberikan pendidikan kesehatan dengan media Booklet Anti ISPA (BOOKIS) sebagian besar tetap perilakunya baik dalam pencegahan ISPA setelah diberikan pendidikan kesehatan dengan media Booklet Anti ISPA (BOOKIS) dengan persentase $57,4 \%$, sedangkan tidak ada yang memiliki perilaku yang kurang sebelum diberikan pendidikan kesehatan dengan media BookletAnti ISPA (BOOKIS). Hal ini dipenaruhi oleh pemberian pendidikan kesehatan dengan media BookletAnti ISPA (BOOKIS) kepada respoden sehingga perilaku pencegahan responden yang semula cukup nhenjadi baik.

$\boldsymbol{V a} \quad$ Hasil analisis bivariat menggunakan uji wilcoxon dan diperoleh nilai $\mathrm{p}=0,000$. Karena nilai $\mathrm{p}<\alpha(0,05)$, maka $\mathrm{H} 0$ ditolak.

Hal ini berarti bahwa ada pengaruh pendidikan kesehatan dengan media Booklet Anti ISPA (BOOKIS) terhadap perilaku pencegahan ISPA pada ibu balita di Banjar Kurang $\quad \begin{array}{llllll}0 & 0 & 0 & 0 & 0 & 0\end{array}$

$\begin{array}{ccccccc}\text { Cukup } & 2 & 3,3 & 2 & 39, & 2 & 42 \\ & & 4 & 3 & 6 & , 6 \\ \text { Baik } & 0 & 0 & 3 & 57, & 3 & 57 \\ & & & 5 & 4 & 5 & , 4\end{array}$


Ni Putu Diah Ameliya PutridanI Ketut Gama. Desember 2020. 13 (2). 87-96

Tabel 9

Tabel Silang Pendidikan Ibu Balita Pekerja Kura Cukup Baik ah an ng

Dengan Perilaku Pencegahan ISPA

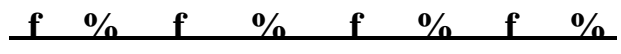

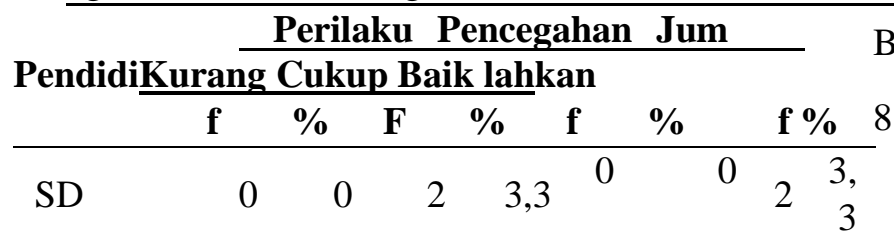

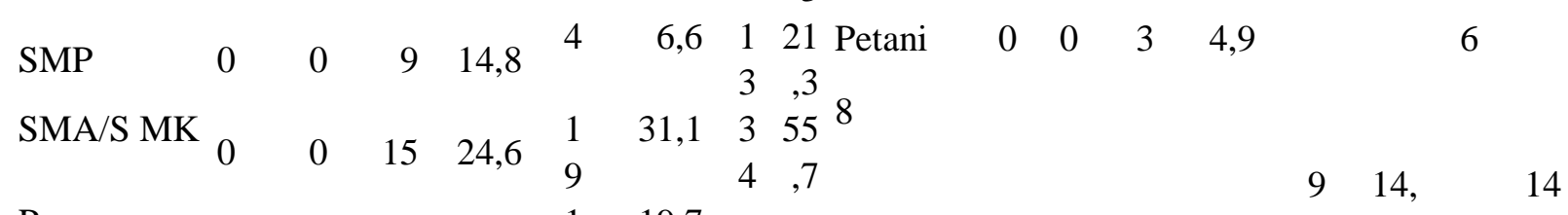

\begin{tabular}{|c|c|c|c|c|c|c|c|c|}
\hline $\begin{array}{l}\text { Perguruan } \\
\text { Tinggi }\end{array}$ & 0 & 0 & 0 & 0 & $\begin{array}{l}1 \\
2\end{array}$ & 19,7 & $\begin{array}{l}1 \\
2\end{array}$ & 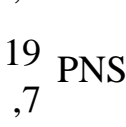 \\
\hline Jumlah & 0 & 0 & 26 & 42,6 & 35 & 57,4 & $\begin{array}{l}6 \\
1 \\
\end{array}$ & $\begin{array}{r}10 \\
0\end{array}$ \\
\hline
\end{tabular}

Berdasarkan interpretasi tabel 9 diatas, dari 61 responden di Banjar Negari didapatkan bahwa sebagian besar ibu balita yang berpendidikan terakhir SD semuanya memiliki perilaku pencegahan ISPA yan cukup dengan persentase $3,3 \%$, ibu balita yang berpendidikan terakhir SMP sebagian besar memiliki perilaku pencegahan ISPA yang cukup dengan persentase 21,3\%, ibu balita yang berpendidikan terakhir SMA/SMK sebagian besar memiliki perilaku pencegahan ISPA yang baik dengan persentase $31,1 \%$, sedangkan ibu balita yang berpendidikan terakhir perguruan tinggi semuanya memiliki perilaku pencegahan ISPA yang baik dengan persentase $19,7 \%$.

Tabel 10

Tabel Silang Pekerjaan Ibu Balita Dengan Perilaku Pencegahan ISPA Di Banjar Negari $\begin{array}{lllll}\text { Swasta } & 0 & 0 & 0 & 0\end{array}$

Tidak

11, $\begin{array}{llll}4 & 0 & 4 & , 0\end{array}$

(1)
7 34,9

$\begin{array}{llll}\text { Bekerja } & 5 & 0 & , 4\end{array}$ Wirasw $118, \quad 126$ $\begin{array}{llll}0 & 0 & 5 & 8,2\end{array}$

asta

$\begin{array}{llll}1 & 0 & 6 & 2\end{array}$

\begin{tabular}{rcccccccr}
\hline \multirow{3}{*}{ Jumlah } & 7 & 5 & 7 & 27,9 & 7 & 60 & 6 & 10 \\
\hline
\end{tabular}

Berdasarkan interpretasi tabel 10 diatas, didapatkan bahwa ibu balita yang bekerja sebagian besar memiliki perilaku pencegahan ISPA yang baik dengan persentase $50,8 \%$, sedangkan ibu balita yang tidak bekerja sebagian besar memiliki perilaku pencegahan ISPA yang cukup dengan persentase $9,8 \%$.

\section{SIMPULAN}

Juml

Berdasarkan

karakteristik responden dari 61 sampel penelitian, Jurnal Gema Keperawatan |Volume 13|Nomor 2| 94 
pengetahuan ibu sebelum diberikan pendidikan kesehatan dengan media Booklet Anti ISPA (BOOKIS) sebanyak $(50,8 \%)$ pengetahuannya baik, setelah diberikan pendidikan kesehatan dengan media Booklet Anti ISPA (BOOKIS) sebanyak $(75,4 \%)$ pengetahuannyaa baik. Sikap ibu balita tentang pencegahan ISPA sikap sebelum diberikan pendidikan kesehatan dengan media Booklet Anti ISPA (BOOKIS) sebanyak (73,8\%) sikapnya baik terhadap pencegahan ISPA, setelah diberikan pendidikan kesehatan dengan media Booklet Anti ISPA (BOOKIS) sebanyak $(98,4 \%)$ sikapnya baik terhadap pencegahan ISPA. Tindakan pencegahan ISPA pada balita sebelum diberikan pendidikan kesehatan dengan media Booklet Anti ISPA (BOOKIS) sebanyak $(54,2 \%)$ tindakannya baik dalam pencegahan ISPA, setelah diberikan pendidikan kesehatan dengan media Booklet Anti ISPA (BOOKIS) sebanyak $(60,7 \%)$ tindakannya baik dalam pencegahan ISPA. Perilaku pencegahan sebelum diberikan pendidikan kesehatan dengan media Booklet Anti ISPA (BOOKIS) sebanyak $(57,4 \%)$ perilakunya baik dalam pencegahan ISPA, setelah diberikan pendidikan kesehatan dengan media Booklet Anti ISPA (BOOKIS) sebanyak $(96,7 \%)$ perilakunya baik dalam pencegahan ISPA. Ada pengaruh pendidikan kesehatan dengan media Booklet Anti ISPA (BOOKIS) terhadap perilaku pencegahan ISPA pada ibu balita di Banjar Negari, Desa Singapadu Tengah tahun 2019 dengan nilai $p$-value pada kolom Sig. $(2$-tailed $)=0,000$ nilai $\mathrm{p}<\alpha$ $(0,05)$.

\section{UCAPAN TERIMAKASIH}

Peneliti mengucapkan terimakasih kepada PoltekkesKemenkes Denpasar sebagai institusi tempat peneliti bernaung, dosen pembimbing yang memberikan masukan, pengetahuan dan bimbingan dalam menyelesaikan penelitian ini, Kelian Dinas Banjar Negari yang telah memberikan izin peneitian dan mendampingi selama proses penelitian, dan semua pihak yang terlibat dan telah membantu dalam penelitian ini yang tidak bisa peneliti sebutkan satu persatu.

\section{ETIKA PENELITIAN}

Etika dalam penelitian ini meliputi autonomy/menghormati harkat dan martabat manusia, confidentiality/kerahasiaan, justice/keadilan, serta beneficiencedan non maleficience. Persetujuan etika dalam penelitian ini diperoleh di komisi etik penelitian kesehatan (KEPK) PoltekkesKemenkes Denpasar, dengan nomor surat

\section{LB.02.03/EA/KEPK/0147/2019}

\section{SUMBER DANA}

Sumber dana dalam penelitian ini sepenuhnya berumber dari peneliti (swadana).

\section{DAFTAR PUSTAKA}

1. Notoatmodjo. Promosi Kesehatan dan Ilmu Perilaku. Jakarta: Rineka Cipta; 2013.

2. Kementerian Kesehatan RI. Riset Kesehatan Dasar Laporan Nasional 2013. Jakarta; 2013.

3. WHO. Child Mortality. 2017.

4. Dinas Kesehatan Provinsi Bali. Profil Kesehatan Provinsi Bali 2017. Denpasar; 2018.

5. Dinas Kesehatan Kabupaten 
Ni Putu Diah Ameliya PutridanI Ketut Gama. Desember 2020. 13 (2). 87-96

Gianyar. Profil Kesehatan Kabupaten Gianyar. Gianyar; 2018.

6. UPT Kesmas Sukawati. Profil UPT Kesmas Sukawati II Tahun 2017. Gianyar; 2018.

7. Fitriani. Promosi Kesehatan. Yogyakarta: Graha Ilmu; 2011.

8. Ma’Munah M. Pengaruh Pendidikan Kesehatan dengan Booklet terhadap Pengetahuan Nutrisi Ibu Laktasi di Wilayah Kerja Puskesmas Ciputat Timur. 2015;

9. Arsyad A. Media Pembelajaran. Jakarta: PT Raja Gravindo Persada; 2007.

10. Mahmudah E. Pengaruh Penyuluhan Dengan Media Booklet Terhadap
Praktik Ibu Dalam Memberikan Pengetahuan Personal Hygiene Saat Menstruasi Pada Anak Berkebutuhan Khusus. 2018;

11. Fatmawati TY. Pengaruh Pendidikan Kesehatan dengan Media Leaflet terhadap Perilaku Ibu tentang Pencegahan ISPA pada Balita di Posyandu. 2017;17(3):227-34.

12. Mariati N. Pengaruh Pendidikan Kesehatan ISPA terhadap Sikap Ibu dalam Pencegahan ISPA pada Balita. 2014;

13. Notoatmodjo S. Kesehatan Masyarakat Ilmu \& Seni. Jakarta: Rineka Cipta; 2011. 